EPJ Web of Conferences 33, 01010 (2012)

DOI: $10.1051 /$ epjconf/20123301010

(C) Owned by the authors, published by EDP Sciences, 2012

\title{
The method of assessment of solar potential for selected area with use Geographical Information Systems
}

\author{
M. Pietras ${ }^{1, \mathrm{a}}$, P.Netzel $^{2, \mathrm{~b}}$ \\ ${ }^{1}$ University of Wroclaw, Department of Climatology and Atmosphere Protection, Poland \\ ${ }^{2}$ University of Wroclaw, Department of Climatology and Atmosphere Protection, Poland
}

\begin{abstract}
This paper describes a method for analyse the spatial distribution of solar energy potential based on calculated solar irradiation with use of GIS (Geographical Information System). Program GIS GRASS gives opportunity to create spatial distribution of solar radiation which is taking into account such important elements like: terrain, atmosphere, pollutants, water and aerosol in atmosphere, clouds. The use of GIS GRASS module - named r.sun gives opportunity to generate spatial distribution of solar radiation on Lower Silesia (south - west part of Poland). In this work the analyse of solar potential to obtain hot water in the individual household were done. This analyse was based on the amount of total solar radiation monthly sums generated by r.sun module. Spatial distribution of solar potential was used to classify the Lower Silesia region in terms of work efficiency solar installations. It is very usefully because it gives people information about the date of the return of the funds invested in the purchase of the solar collectors.
\end{abstract}

\section{Introduction}

The main goal of this study is to analyse the spatial distribution of solar radiation, which is determined by numerous elements, such as: terrain, atmosphere, pollutants, water and aerosol in atmosphere, clouds.

The key problem is the solar radiation incident on a regional scale, i.e. the Lower Silesia region. In such a case, the major factor modifying the distributions of the radiation is the terrain (e.g. slopes and aspects). Apart from it, the local shadowing effects of the terrain are of no less importance.

Another crucial element of the solar analysis is the cloud cover. As the clouds constitute a barrier for the sun radiation, the solar radiation models should include the cloud cover. This problem was examined in numerous studies and some authors used data from the local ground stations to determine the range of the clouds. However, such data is reliable exclusively for a region surrounding the station.

Summing up, all the above elements should be included to properly assess the spatial and temporal variation of the solar radiation. It is GRASS that gives such a possibility.

\subsection{The reason for estimate solar energy potential}

Knowledge about solar potential can be useful to analyse the possibility of reduce air pollutants when solar collectors will be used to prepare hot water in individual household in Lower Silesia region.

\footnotetext{
${ }^{a}$ e-mail:malgorzata.pietras@uni.wroc.pl

b e-mail: pawel.netzel@uni.wroc.pl
} 
New energy politics of the European Union [7] assumes the reduction of the greenhouse gases emission and at the same time the increase of the use renewable energy sources. This goals are possible but first the analyse of the renewable energy sources in local scale should be done.

Most studies on the sun energy as an energy source is based on measurement data from the point of ground stations $[1,2]$.

In previous works often analysed the distributions of total radiation without considering the parameter cloud - clear sky radiation [5]. Resent works contains complex studies about solar potential of Europe was made by scientists working for Joint Research Centre (JRC). They calculate spatial distribution of total solar radiation for European Union in resolution $1 \times 1 \mathrm{~km}$ [10].

\section{GRASS as an example of Geographic Information Systems}

GRASS is a GIS (Geographic Information System) software package. The word "package" describes GRASS very well. GRASS is set of commands (so called modules or simpler - executable programs) working in common environment and using a GRASS dedicated spatial database. Because of such architecture, GRASS is used not only as a desktop GIS system. It serves as calculation engine in server-client architecture, as a core of OGC WPS (Web Processing Service) server (pyWPS), as a spatial calculations library for other desktop programs (QuantumGIS etc.). GRASS belongs to the category of software called FOSS - Free Open Source Software. It is released with GNU GPL license and it is available for downloading form GRASS internet web page [8] or from many mirros. For example, form polish mirror of GRASS in the Department of Climatology and Atmosphere Protection, University of Wroclaw [9]. GRASS is very easy to learn and use. User needs only to know selected, relatively small, set of commands/programs to work with GRASS. Besides of general tools for viewing data, import/export data, general spatial calculations, there are many programs focused on particulars modelling problems in GRASS. One of these specialized programs is the module for solar irradiation modelling - r.sun.

\section{About r.sun}

The r.sun is one of the GRASS commands. It is used to analyse the spatial distribution of solar radiation [3]. The parameters of the r.sun has already been described by Pietras [6].

Mainly, it is working based on a terrain model and its derivatives (slope, aspect, etc.), atmospheric parameters (LTF, Cc, etc.) and astronomical calculations (Sun azimuth and elevation for a given location on Earth, etc.).

r.sun model computes direct, diffuse and reflected solar irradiation. It produces raster maps for given day, latitude, terrain and atmospheric conditions. Solar parameters (e.g. sunrise, sunset times, declination, extraterrestrial irradiation, daylight length) are saved in the map history file. The shadowing effect of the topography is optionally incorporated [-s option].

Because of large set of parameters, the syntax of r.sun is complicated. But, many of parameters are optional and many have default values.

The user can script the processing. It allows to perform calculations for a selected set of days to compute radiation for some time interval within the year (e.g. vegetation or winter period, months). Scripting r.sun calculations also gives an opportunity to store data about each day, to take into account real atmospheric parameters for each day, to add extra calculations (for example to calculate solar energy production by a model of solar panel).

r.sun, as an GRASS command, uses GRASS spatial database to read data and store results. Using scripts, one can store their own calculation's results in extra text files. 


\section{Input data}

Input data for solar analyses was the numerical model of a terrain for a selected area, the maps of the slopes and aspects, the atmospheric turbidity data, in this case a Linke Turbidity Factor (LTF) and cloud cover parameters Cc.

The model of the terrain used in this work had the resolution of 100 meters and covers the area of the Lower Silesia. The maps of the slopes and aspects were created with the use of the r.slope.aspect command in GRASS.

\subsection{Atmospheric turbidity factor}

As for the atmospheric turbidity data, in this study it was gathered by the use of the Linke Turbidity Factor (LTF). The size of this factor depends on the solar elevation angle, the water vapour and the contents of the aerosols in the atmosphere. The LTE coefficient medium value in temperate latitudes is 3.0, but in the cities where atmosphere is polluted its value may exceed 3.5.

In this work the value of LTF was taken from Hofierka [3] previous work (Tab.1). The monthly averages of the Linke turbidity factor is here correlated with the type of surface use. Information about type of use surface was taken form Corine database.

Finally 12 raster maps was generated - one for every month - with the LTF parameters.

Table 1. Mounty average of LTF for different type of surface use

\begin{tabular}{|c|c|c|c|c|c|c|c|c|c|c|c|c|}
\hline Month & I & II & III & IV & V & VI & VII & VIII & IX & X & XI & XII \\
\hline $\begin{array}{c}\text { Urban } \\
\text { area }\end{array}$ & 3.1 & 3.2 & 3.5 & 4.0 & 4.2 & 4.3 & 4.4 & 4.3 & 4.0 & 3.6 & 3.3 & 3.1 \\
\hline $\begin{array}{c}\text { Rural } \\
\text { area }\end{array}$ & 2.1 & 2.2 & 2.5 & 2.9 & 3.2 & 3.4 & 3.5 & 3.3 & 2.9 & 2.6 & 2.3 & 2.2 \\
\hline $\begin{array}{c}\text { Mountain } \\
\text { area }\end{array}$ & 1.5 & 1.6 & 1.8 & 1.9 & 2.0 & 2.3 & 2.3 & 2.3 & 2.1 & 1.8 & 1.6 & 1.5 \\
\hline
\end{tabular}

\subsection{Cloud cover parameters}

Cloud cover parameters was calculated from the empirical formula proposed by Kasten and Czeplak [4].

$$
C c=1-0.75(N / 8)^{3.4}
$$

Where $N$ is a parameter describing the daily average cloudiness of the sky. this value was calculated on the base of information available on line as an synoptic telegram. With use of synoptic data from 8 meteorological station on the Lower Silesia region: Jelenia Gora, Legnica, Leszno, Kalisz, Klodzko, Opole, Wrocław, Zielona Gora. The value of Cc parameter was calculate.

Next step was to generate the raster maps contains the value of $\mathrm{Cc}$ parameters for selected area. It was created using interpolation: v.surf.rst comand. This map was generated for every month. 


\section{Global irradiation on a horizontal surface}

First step to calculate monthly sums of total solar irradiation in real-sky conditions was to generated the monthly sums of total solar irradiations in the clear-sky conditions. It was done on the base of numerical terrain model (DEM) and the Linke turbidity factor (LTF) with use r.sun comand. Finally global irradiation for real-sky conditions $(G)$ was calculated using the clear-sky radiation (Ghc) generated by r.sun and the clear-sky index $(\mathrm{Cc})$ with following formula:

$$
G=G h c \times C c
$$

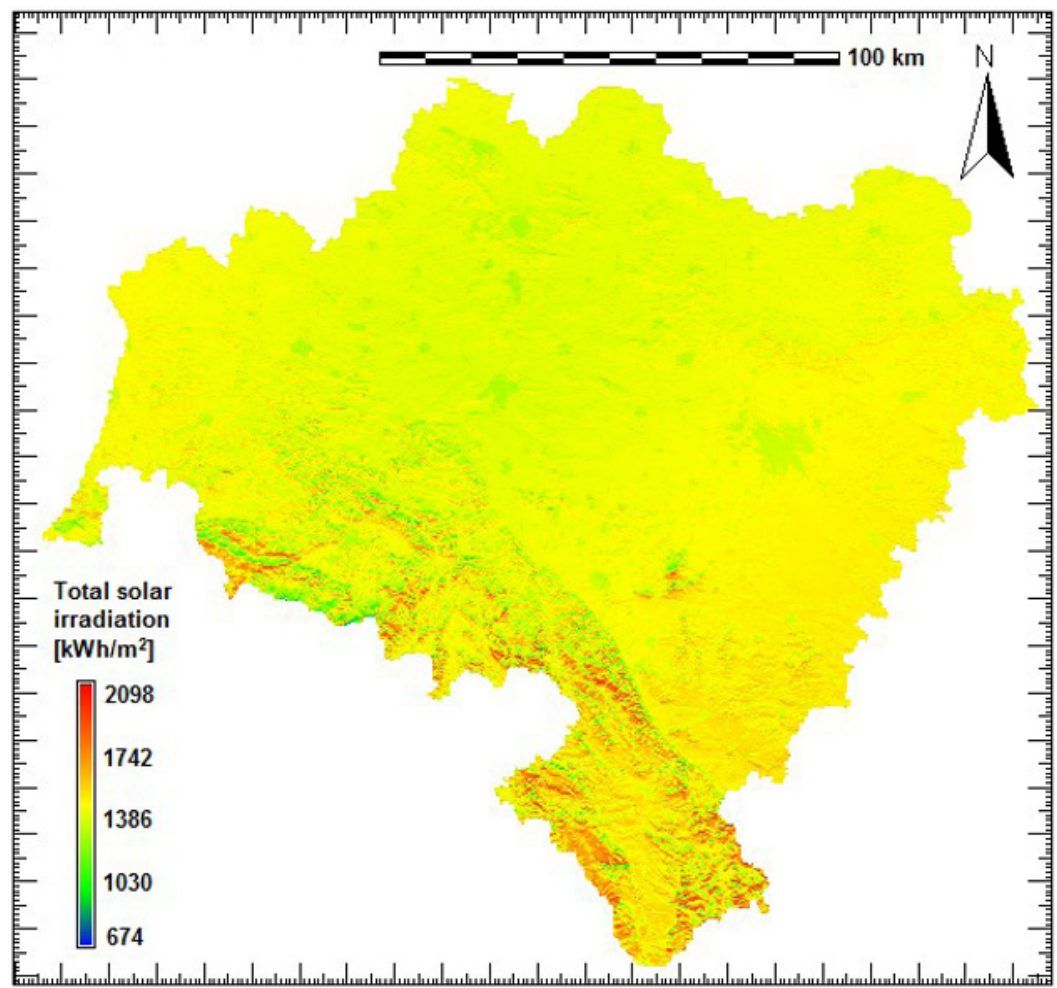

Fig. 2. Spatial distribution of solar radiation (real-sky conditions) on Lower Silesia

The map of the solar potential on the Lower Silesia region generated with use of r.sun module (Fig. 2) would allow everyone to check the solar potential of their region.

\section{Spatial distribution of solar energy potential}

The spatial distribution of solar energy is here presented as a potential of the solar radiation energy used to obtain hot water in individual household.

Generated map of spatial distribution of solar radiation on Lower Silesia will broaden people's knowledge about the opportunity of use solar energy. This elaboration is dedicated to local communities, as well as for businesses concerning at the environment protection and the climatic change problems. This map is also a base to classify the Lower Silesia region in terms of work efficiency solar installation (Fig.3). It will gives people information about the date of the return of the funds invested in the purchase of the solar collectors. 


\section{$2^{\text {nd }}$ European Energy Conference}

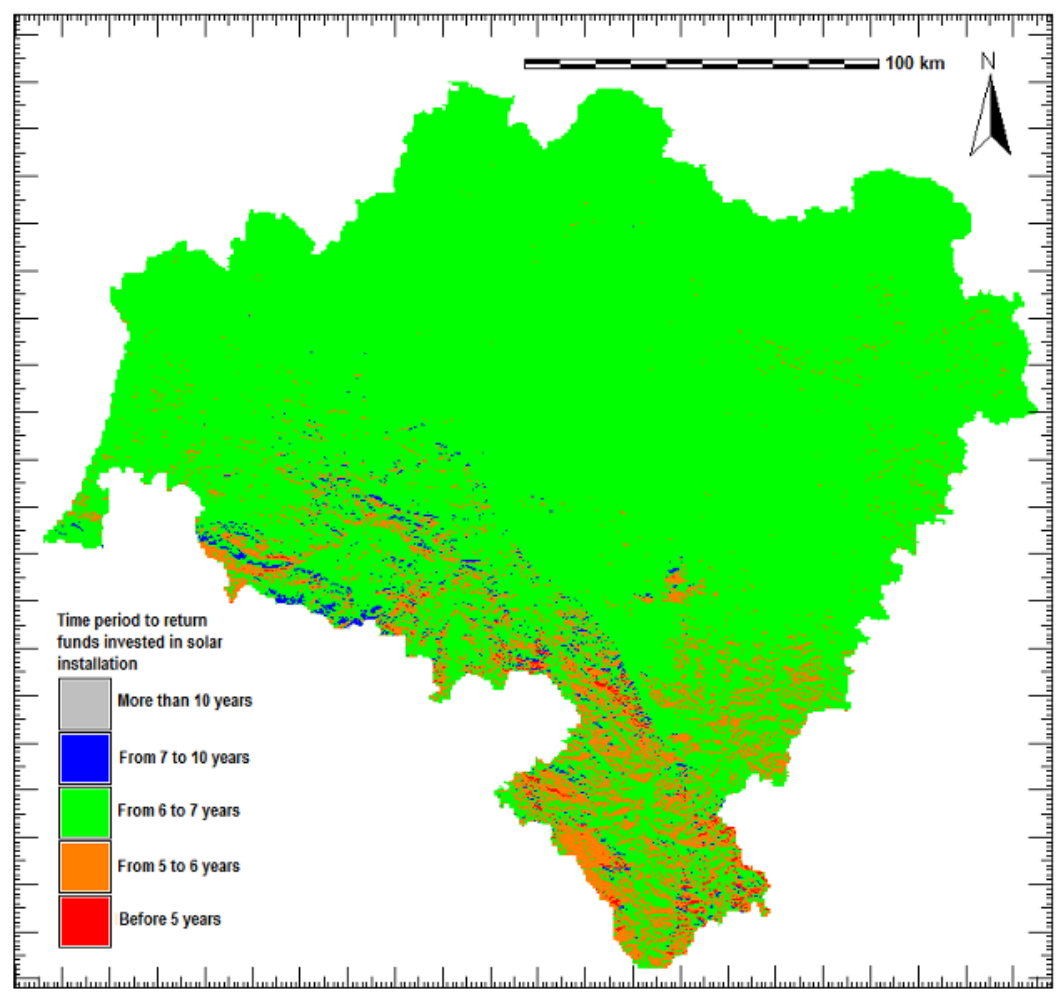

Fig. 3. Classification of the Lower Silesia region in terms of work efficiency solar installations

\section{Results}

The use of the r.sun model to calculate the total solar radiation for the large area, covering the Lower Silesia region, gives good results, they prove to be compatible with the values obtained using HelioClim (Tab.2) and with measurement values (Tab.3).

The modelling accuracy of the r.sun values was evaluated against the input meteorological data used in the computation and with the HelioClim database.

HelioClim is a family of databases which comprise solar irradiance and irradiation values available at ground level. HelioClim cover Europe, Africa, the Mediterranean Basin, the Atlantic Ocean and part of the Indian Ocean. In this study HelioClim data was used as a reliable source for verification of results obtained through r.sun model.

Comparing the monthly sum of the global horizontal irradiation with the value of monthly sum from meteorological measurements give satisfactory results. The mean bias error (MBE) is $13,3 \%$. The biggest error was found for July and it was $30,2 \%$. The smallest error was for February $-3,0 \%$. 


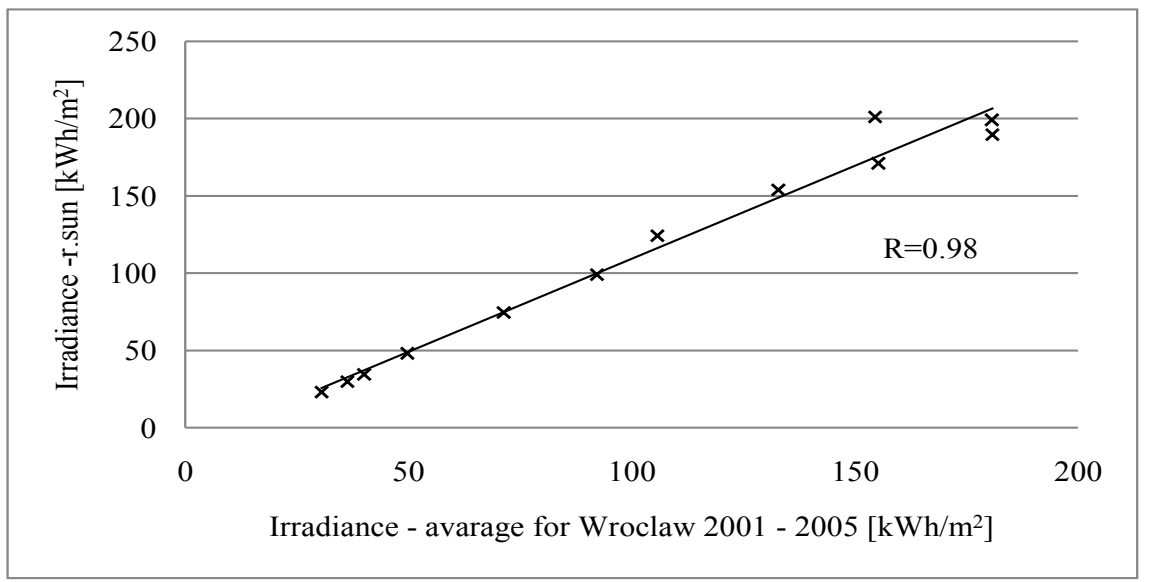

Fig. 1. Correlations of the measured value and generated by r.sun module.

Results obtained with r.sun perfectly reflect annual course of solar radiation. The biggest difference between measurement and modelled value appear during the summer months and they are about a dozen $\mathrm{kWh} / \mathrm{m}^{2}$ bigger then measurement value of irradiation in case of Wroclaw. In winter months it is difference only a few $\mathrm{kWh} / \mathrm{m}^{2}$. (Tab.2).

Table 2. Summary of r.sun model performance

\begin{tabular}{|c|c|c|c|c|c|c|c|c|}
\hline \multirow[b]{2}{*}{ Month } & \multicolumn{4}{|c|}{ HelioClim ${ }^{1}\left[\mathrm{kWh} / \mathrm{m}^{2}\right]$} & \multicolumn{4}{|c|}{ r.sun $\left[\mathrm{kWh} / \mathrm{m}^{2}\right]$} \\
\hline & Wroclaw & Kłodzko & Legnica & \begin{tabular}{|c|} 
Jelenia \\
Góra
\end{tabular} & Wroclaw & Kłodzko & Legnica & $\begin{array}{c}\text { Jelenia } \\
\text { Góra }\end{array}$ \\
\hline I & 24,8 & 26,6 & 24,5 & 19,0 & 29,8 & 32,6 & 27,9 & 31,6 \\
\hline II & 45,7 & 45,3 & 46,6 & 29,8 & 48,2 & 49,4 & 45,7 & 49,3 \\
\hline III & 76,2 & 74,5 & 79,2 & 56,1 & 99 & 103,7 & 91,7 & 96,1 \\
\hline IV & 127,4 & 123,9 & 136,0 & 97,0 & 153,9 & 159,4 & 145,2 & 150,7 \\
\hline V & 164,8 & 167,9 & 159,2 & 125,5 & 189,6 & 195,0 & 179,0 & 183,5 \\
\hline VI & 150,6 & 146,8 & 150,6 & 124,2 & 199,2 & 203,7 & 190,9 & 195,5 \\
\hline VII & 138,4 & 136,2 & 137,4 & 115,6 & 201,1 & 205,4 & 192,8 & 194,1 \\
\hline VIII & 158,2 & 152,0 & 156,6 & 118,1 & 171,1 & 176,4 & 162,5 & 166,0 \\
\hline IX & 104,0 & 100,7 & 107,6 & 74,6 & 124,2 & 125,8 & 119,0 & 118,6 \\
\hline $\mathrm{X}$ & 61,3 & 60,0 & 62,5 & 43,6 & 74,6 & 76,1 & 69,5 & 72,4 \\
\hline XI & 31,7 & 33,2 & 32,1 & 23,3 & 34,5 & 37,1 & 31,4 & 34,9 \\
\hline XII & 28,9 & 30,3 & 26,7 & 17,8 & 23,2 & 25,4 & 21,0 & 24,5 \\
\hline Year & 1111,9 & 1097,5 & 1118,9 & 844,7 & 1348,4 & 1390,0 & 1276,7 & 1317,2 \\
\hline
\end{tabular}


Table 3. r.sun model verification

\begin{tabular}{|c|c|c|c|c|}
\hline \multicolumn{5}{|c|}{ Wroclaw [kWh/m ${ }^{2}$ ] } \\
\hline Month & $\begin{array}{c}\text { Average } \\
\mathbf{2 0 0 1 -} \\
\mathbf{2 0 0 5}\end{array}$ & $\begin{array}{c}\text { Difference } \\
\text { between } \\
\text { modeled by } \\
\text { r.sun and } \\
\text { measured value }\end{array}$ & MBE [\%] \\
\hline I & 36,3 & 29,8 & $-6,5$ & 17,9 \\
\hline II & 49,7 & 48,2 & $-1,6$ & 3,0 \\
\hline III & 92,2 & 99,1 & 6,8 & 7,5 \\
\hline IV & 132,8 & 153,9 & 21,1 & 15,9 \\
\hline V & 180,8 & 189,6 & 8,8 & 4,9 \\
\hline VI & 180,7 & 199,2 & 18,5 & 10,2 \\
\hline VII & 154,5 & 201,1 & 46,6 & 30,2 \\
\hline VIII & 155,2 & 171,1 & 15,9 & 10,2 \\
\hline IX & 105,8 & 124,2 & 18,4 & 17,4 \\
\hline X & 71,3 & 74,6 & 3,3 & 4,6 \\
\hline XI & 40,1 & 34,5 & $-5,5$ & 14,0 \\
\hline XII & 30,5 & 23,2 & $-7,4$ & 23,9 \\
\hline & Average MBE [\%] & 13,3 \\
\hline
\end{tabular}

The Pearson's correlation coefficient of the value measured and modelled with by r.sun is equal 0.98, which also proves the reliability of the results obtained by the r.sun model (Fig .1).

\section{Conclusions}

A spatially modelling of potential solar energy can be very useful for making decision where to use solar panel installations, where is it economically reasonable. Modelling with use of GIS tools can answer for such question.

GRASS, more precisely - r.sun, provides good quality information needed by solar energy modelling.

The high resolution data produced by GRASS model $(100 \times 100 \mathrm{~m})$ allows us to point most convenient areas for using solar panels.

The advantage of our approach is comparing the terrain features with changes in radiation fields and considering the shadowing effects. The use of the $\mathrm{Cc}$ raster maps give better fit the regional specifications of radiation in the mountainous areas. The influence of terrain shading is visible if applied of resolution data $-100 \times 100 \mathrm{~m}$. This have meaning especially in mountain areas.

In future work it should be calculated model errors beyond the solid measured points. It will raised the possibility of the more precise fit of the model.

At the second stage, it is possible to model final locations using detailed DEM data (with information about building heights, tree heights etc.) with resolution higher than one meter. Such high resolution data are available thanks lidar scans. One can find in GRASS proper tools for processing lidar scan data as well as high resolution DEM information. 
Therefore GIS programs, in this case GRASS, can be a helpful in the case studies assessing the potential of renewable energy for example solar energy.

\section{References}

1. Adsten M., Perers B., Wackelgad E., The influence of climate and location on collector performance, Renewable energy, 25, 499-509 p., (2000)

2. Danielewicz J., Szulgowska-Zgrzywa M., A simulation of the solar collector work by means of the model describing daily heat gains, Polish Journal of Environment Study, 16, No 3B/2007, 82-89 p., (2007)

3. Hofierka, J., Suri, M., The solar radiation model for Open source GIS: implementation and applications. Manuscript submitted to the International GRASS users conference in Trento, Italy (2002).,

4. Kasten F., Czeplak G., Solar and terrestrial radiation dependent on the amount and type of cloud, Solar Energy, 24, (1979),

5. Kryza M., Szymanowski M., Migała K., Pietras M., Spatial information on total solar radiation: application and evaluation of the r.sun model for the Wedel Jarlsberg Land, Svalbard. Polish Polar Res., 31 (1), 17-32 p., (2010),

6. Pietras M., 2011, Moduł r.sun - wykorzystanie do obliczania wydajności kolektorów słonecznych [in]: Netzel P. (ed.) Analizy przestrzenne z wykorzystaniem GRASS. Rozprawy Naukowe Instytutu geografii i Rozwoju Regionalnego 15, Uniwersytet Wrocławski, (2011).

7. The European Commission, Communication from the Commission to the European Parliament, the Council, the European Economic - Social Committee of the Regions, Action Plan leading to a transition to a competitive low carbon economy by 2050, Brussels, (2011),

8. http://grass.osgeo.org/

9. http://grass.meteo.uni.wroc.pl/

10. http://re.jrc.ec.europa.eu/pvgis/ 